\title{
AC 2010-223: ENHANCING THE LEARNING EXPERIENCE IN A MULTIDISCIPLINARY ENGINEERING TECHNOLOGY COURSE
}

\section{Rocio Alba-Flores, Georgia Southern University}

Rocio Alba-Flores received her M.S. and Ph.D. in Electrical Engineering from Tulane University. She is an Assistant Professor in the Department of Mechanical and Electrical Engineering Technology at Georgia Southern University. Her main areas of interest include control systems, robotics, digital systems, microprocessors, and signal and image processing.

Youakim Al Kalaani, Georgia Southern University 


\title{
Enhancing the Learning Experience in a Multidisciplinary Engineering Technology Course
}

\begin{abstract}
Rapidly changing technology advances demand the revisions of engineering and technology courses so that they continue to serve students and industry in a relevant way. In a typical engineering technology department, students from different majors are usually required to take an introductory electrical engineering course. Due to the multidisciplinary background of students, such a course has traditionally been a challenge to teach so as to make it interesting and useful to all students. Therefore innovative teaching methods have to be employed in order to accommodate different backgrounds and learning styles.
\end{abstract}

In our department, a basic electrical engineering course is offered for sophomore students majoring in mechanical and electrical engineering technology. The course is usually taught in the fall and is meant to be an introductory course for EET students but also serves as a survey of electrical engineering for MET students. Because of this duality, the course has to be carefully designed, especially the laboratory component, to keep students interested and engaged throughout the semester. Topics covered include dc and ac circuits, Wheatstone bridge, electric machines, resonance circuits, RLC transient response, basic operation of electronics and digital circuits including diodes, transistors, power supplies, amplifiers, and logic gates.

In this paper, we describe our experience teaching the course and how the redesign of the laboratory component has greatly enhanced the student learning experience independently of their majors of studies. Results showed that activities relating concepts to real world applications were more appealing. For instance, students enjoyed performing experiments involving the use of transducers such as strain gauges. Assessments results to meet certain accreditation criteria including direct and indirect measurements are also discussed with emphasis on the successes and lessons learned from the implementation process.

\section{Introduction}

Engineering and Technology education faces significant challenges in its attempt to meet the demands of the engineering profession in the $21^{\text {st }}$ century. The rapid changing in technology necessitates the revisions of topics taught so that they continue to serve students and industry in a pertinent way. During the last decade many articles have been published ${ }^{1,2,3}$ calling for reform and proposing new methods for undergraduate engineering education including improvements of the classroom environment, and asserting the desire to attract and retain a diverse student body.

In a typical ET department, students from different majors are usually required to take an introductory electricity course. Due to its multidisciplinary nature, such a course has traditionally been a challenge to teach and therefore innovative teaching methods have to be employed. In our department, this course is called "Electrical Devices \& Measurements" and offered mostly to Mechanical (MET) and Electrical (EET) Engineering Technology students, in addition to others who can take it as an elective course in their major of studies. Therefore students taking this 
course have a wide range of capabilities, varied preparation, and different levels of motivation that entail a more complex teaching strategy than a traditional course would normally require. Moreover, retention rate may severely be affected if struggling students were not adequately motivated to continue their pursuit of an engineering career. With this in mind, faculty teaching this course decided to make fundamental changes starting with a comprehensive review to analyze the course content and assessment results obtained from previous years. During this process, some limitation factors were discovered such as- 1) The course contents were mainly targeted for electrical engineering major, neglecting other engineering disciplines; 2) Too much emphasis was placed on circuit analysis techniques with no "real world" context provided; 3) Laboratory activities were step-by-step and focused on verifying lecture content rather than on discovery of concepts; and 4) Computers and state-of-the-art simulation software were not used or underutilized. Based on these observations, the course was revised with a completely new set of lab experiment focused on verifying concepts with real world applications. More computer work has also been added including a tutoring type interactive software and NI-MultiSim to allow students to perform circuit simulation as pre-lab assignments.

In the next several sections, we will provide details about the revision process and discuss assessments results to illustrate the effectiveness of the implemented changes.

\section{Course Description}

The Electrical Devices \& Measurements is a 4-credits course offered in the fall for MET and EET students at the sophomore level. The course has a lab component with a 3 hrs-lecture, $2 \mathrm{hrs}-$ lab per week format that provides the basics in the field of electricity and electronics. Topics covered include basic circuit theory, energy conversion, electric machines, relays and transformers, and an overview of semiconductors and digital circuits including basic electronic devices and sensors.

The laboratory experiments for this course were typically involving small electric circuits such as connecting resistors in series and parallel and collect measurements to verify Ohms law and power computations. Although this type of experiments serves well to reinforce concepts, they definitely were repetitive and somewhat boring to a diverse student body. Based on feedback from faculty and students, the course contents were revised to introduce topics that provide special skills required by MET students such as instrumentation and the practical applications of Wheatstone bridge and transducers. Moreover, the covering of $\mathrm{AC}$ vector analysis, transient response, and resonant RLC circuits were expanded to allow students to grasp a better understanding of these concepts. However, major changes were made to the laboratory component of this course for which a lab manual was developed with a completely new set of experimentations dealing with renewable energy and instrumentation.

Since this course is used in the assessment process for ABET accreditation, the learning outcomes were also expanded to include soft skills such as commitment to quality, timeless, and continuous improvement. These new learning objectives and summary of topics are listed in Table 1 and Table 2 respectively. 


Electrical Devices and Measurements Learning Objectives
1. Use ohm's law, power equation, KVL, and KCL to solve electric circuits
2. Determine resistance, voltage, and current in series, parallel, and combinational circuits
3. State the basic concepts and operation of DC and AC machines
4. Determine impedance, power factor, apparent, real, and reactive powers in AC circuits
5. Determine time constants and plot the transient response of RL and RC circuits
6. State the resonance conditions of an RLC circuit and calculate resonant frequency
7. State the basic operation of diodes, transistors, power supplies, and amplifiers
8. Apply the concepts of Wheatstone bridge and transducers
9. Learn to function effectively in laboratory groups
10. Perform experiments in a disciplinary manner using standard electrical laboratory instruments.
11. Communicate effectively through the submission of professional technical reports
12. Investigate a given topic in technology and discuss societal and ethical considerations
13. Understand and have a commitment to quality, timeless, and continuous improvement
14. Draft and simulate the operation of electric circuits using MultiSim
15. Present a technology topic effectively in front of an audience

\section{Table 1- Course Learning Objectives}

\section{Electrical Devices and Measurements Course Content}

- Science of Electricity and Electronics- The Nature of Matter, Static Electricity

- Basic Electrical Circuit- Ohm's Law, Instruments and Measurements, Analog and digital Meters

- Basic Electrical Circuit Materials- Conductors, Common Circuit Devices, Lighting, Resistors.

- Source of Electricity- Wattmeters and WattHours, Efficiency, Chemical Action, Other Sources

- DC Series/Parallel, Combinational Circuits- Principles and Applications, Electrical Diagrams

- Wheatstone Bridge- Applications, Solving for Voltage and Current

- Magnetism- Electric Current and Magnetism . Relays, Buzzer, and Circuit Breakers.

- AC Circuits- Alternating Current, Complex numbers. Phasor concepts, Generators, Oscilloscope

- DC Machines- DC Machine types, Motors and Generators, Applications

- Transformer Principles, Single-Phase and 3-Phase Distribution Systems

- AC Machines- Applications, Induction Motors, Synchronous Motors, Troubleshooting

- Electronics Circuits: Inductance and Capacitance, RCL Networks and Filtering Circuits

- Semiconductors- Transistors, Amplifiers, OP-Amps, IC Technology and circuits

- Digital Circuits- Digital Fundamentals, Logic Gates, Flip-flops, Counters, 7SD

\section{Table 2- Topics Covered in the Course}

\section{Laboratory Experiments}

As previously noted, the most significant revision of the course has been in the laboratory activities. The laboratory has 12 basic stations equipped with digital multimeters, double DC power supplies, variable AC power supplies, signal generators, oscilloscopes, and breadboards to build circuits. Since the number of MET students enrolled in this class is usually the largest (around 60\%), the instructor is inclined to assign one EET student to every team made of up to 3 students. 
As depicted in Table 3, the lab experiments are divided in three main groups. Students spend the first 5 weeks of the semester working on the introductory lab experiments to acquire familiarity with the equipment and safety procedures. Then, the students progress to learn about the oscilloscope and AC signals as well as RLC networks. The last 5 experiments are more oriented towards practical applications and are not the typical experiments found in an introductory electricity course.

These application oriented experiments are the ones that have been more carefully designed with the objective of increasing students' interest and motivation for the electrical engineering field. In the next paragraph, two of these application oriented experiments are described in detail and a brief description for all experiments is provided in the Appendix.

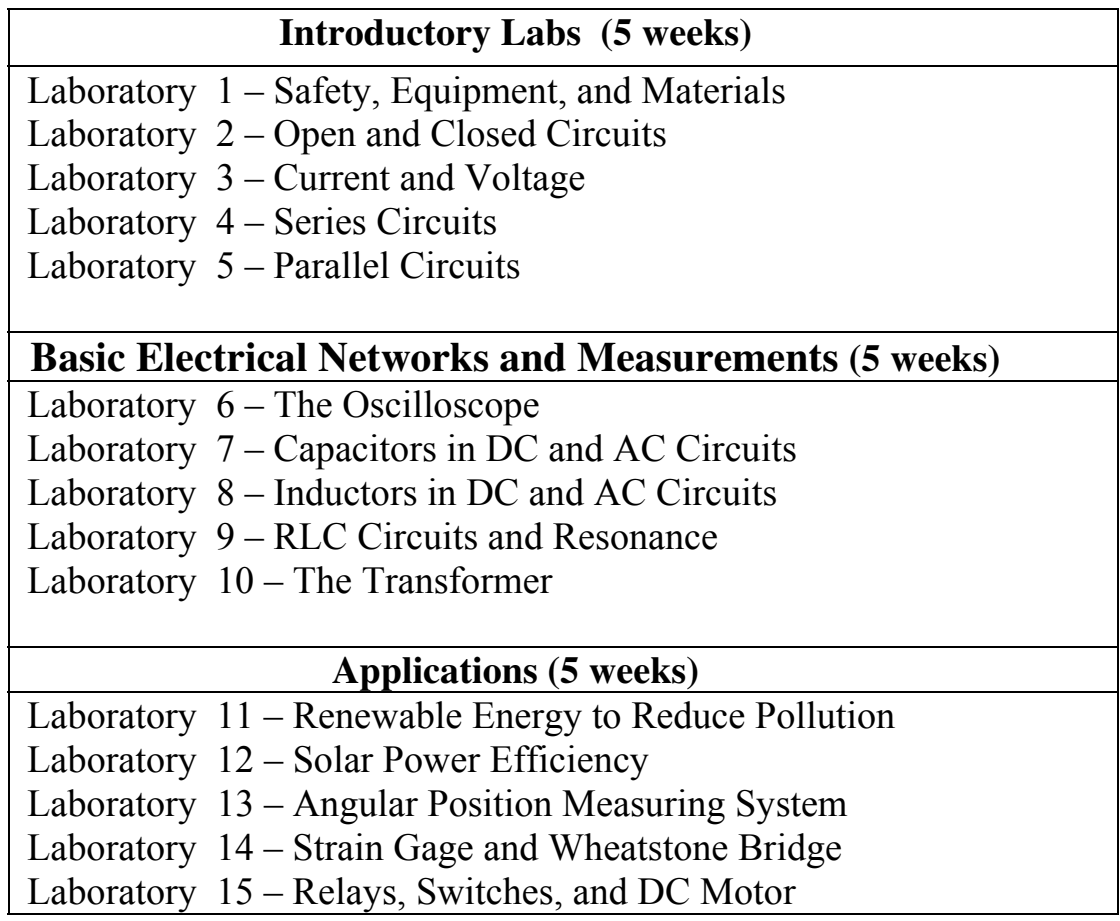

Table 3- Laboratory Experiments

\section{Renewable Energy:}

As described in Table 4, this experiment was developed to introduce students to renewable energy making use of a small solar system on the roof of the technology building and connected to a lab computer via a data acquisition system and the internet. The sensors installed on the system measure temperature, wind speed, solar irradiance, and electric energy produced. Students are expected to use the data to determine, among other things, efficiency and the amount of pollution that can be prevented. 


\section{Laboratory 11. Renewable Energy to Reduce Pollution}

Introduction: In this Lab, we will collect data from the solar energy system and compare it to other ways of countering emissions. There are three major categories of emissions to consider $\mathrm{CO}_{2}$ (carbon dioxide), $\mathrm{SO}_{2}$ (sulfur dioxide), and Nitrogen oxides $\left(\mathrm{NO}_{\mathrm{X}}\right)$. Since these gases are naturally occurring, the question may arise if there is a natural way to deal with them. It has been proven that trees actually absorb some of this pollution. However, how well would tree planting be enough to create an effective "carbon offset" for the United States. We're going to use some data to determine how well this would work.
Important data: $\mathrm{P}=\mathrm{I}_{2} * \mathrm{R} ; \mathrm{P}=\mathrm{I} * \mathrm{~V} ; \mathrm{V}=\mathrm{I} * \mathrm{R}$
$1 \mathrm{btu}=0.000293 \mathrm{~kW}$-hours $=0.293$ watt-hours
$0.000215 \mathrm{lbs}$ of $\mathrm{CO}_{2}$ per btu of energy produced by $\mathrm{Co}$
Some trees can absorb $48 \mathrm{lbs}$ of $\mathrm{CO}_{2}$ per year
212 hectares of Trees absorb $6 \mathrm{lbs}$ of $\mathrm{SO}_{2}$ per day
212 hectares of Trees absorb $9 \mathrm{lbs}$ of $\mathrm{NO}_{\mathrm{X}}$ per day
1 hectare $=2.47105381$ acres
1 ton $=2000 \mathrm{lbs}$

Part I: Carbon Dioxide $\left(\mathbf{C O}_{2}\right)$ Emission. As we discussed previously, Carbon Dioxide contributes to global warming. Over 6 Billion tons of Carbon Dioxide are produced by United States every year.

Step 1- Collect today's solar data from: http://morningstar.fatspaniel.net/tristar/view?\&id=C150010

Use this equation to calculate the $\mathrm{lbs}$ of $\mathrm{CO}_{2}$ emissions per hour the solar energy could produce

Lbs of $\mathrm{CO}_{2}$ emissions per hour $=$ Power $(\mathrm{w}) * 1 \mathrm{btu} / 0.293$ watts-hours $* .000215 \mathrm{lbs}$ per btu

A tree takes in roughly $48 \mathrm{lbs}$. in a year, so use this information to estimate how many trees would be required to offset the emissions of $\mathrm{CO}_{2}$ as follows

- First determine how much $\mathrm{CO}_{2}$ is absorbed by a tree per hour by dividing $481 \mathrm{lbs}$ by the number of hours per year (48 $\mathrm{lbs} / 8760$ hours $=0.0055 \mathrm{lbs}$ per hour).

- Next, the number of trees needed to absorb this amount of $\mathrm{CO}_{2}$ can be determine as:

Number of Trees $=\mathrm{lbs}$ of $\mathrm{CO}_{2}$ avoided per hour $/ 0.0055 \mathrm{lbs}$ per hour

\begin{tabular}{|l|c|c|c|c|c|}
\hline Time of day & $\begin{array}{c}\text { Estimated Voltage } \\
\text { (Volts) }\end{array}$ & $\begin{array}{c}\text { Estimated Current } \\
\text { (Amps) }\end{array}$ & $\begin{array}{c}\text { Power } \\
\text { (Watts) }\end{array}$ & $\begin{array}{c}\text { Lbs. } \mathrm{CO}_{2} \text { emissions } \\
\text { avoided per hour }\end{array}$ & $\begin{array}{c}\text { Number of Trees Required to } \\
\text { offset } \mathrm{CO}_{2} \text { emissions }\end{array}$ \\
\hline 8am & & & & & \\
\hline Solar Noon & & & & & \\
\hline $4 \mathrm{pm}$ & & & & & \\
\hline
\end{tabular}

Part II: Sulfur Dioxide $\left(\mathbf{S O}_{2}\right)$ Emission. Sulfur Dioxide is responsible for increasing the acidity of rainfall in different areas and can cause respiratory problems in vulnerable populations. The EPA estimates that the United States emits 13 million tons of sulfur dioxide (10 millions from electricity generation).

Use this equation to estimate $\mathrm{SO}_{2}$ emissions per hour:

Lbs of $\mathrm{SO}_{2}$ emissions avoided per hour $=\operatorname{Power}(\mathrm{w}) * 1 \mathrm{MWH} / 1000000 \mathrm{WH}^{*} 13 \mathrm{lbs} / \mathrm{MWH}$

- 212 hectares of Trees absorb $6 \mathrm{lbs}$ of $\mathrm{SO}_{2}$ per day or $0.25 \mathrm{lbs}$ per hour

- 1 acre of Trees absorbs $0.0115 \mathrm{lbs}$ of $\mathrm{SO}_{2}$ per day or $0.0000220 \mathrm{lbs}$ per hour

Therefore, the area of trees in acres needed $=\left(\mathrm{lbs}\right.$ of $\mathrm{SO}_{2}$ avoided per hour $) / 0.0000220 \mathrm{lbs}$ per hour

\begin{tabular}{|l|c|c|c|}
\hline \multicolumn{1}{|c|}{ Time of day } & $\begin{array}{c}\text { Power Output } \\
\text { (Watts) }\end{array}$ & $\begin{array}{c}\text { Lbs. } \mathrm{SO}_{2} \text { emissions } \\
\text { avoided per hour }\end{array}$ & $\begin{array}{c}\text { Acres of Trees Required to offset } \\
\mathrm{SO}_{2} \text { emissions }\end{array}$ \\
\hline 8am & & & \\
\hline Solar Noon & & & \\
\hline $4 \mathrm{pm}$ & & & \\
\hline
\end{tabular}

Part III: Nitrogen Dioxide $\left(\mathrm{NO}_{\mathrm{X}}\right)$ Emission

The greatest producer of this chemical is actually automobile emissions. It is a greenhouse gas that contributes to smog and acid rain. The EPA estimates $\mathrm{NO}_{\mathrm{X}}$ emissions at 18 million tons ( 8 millions come from automobiles).

Use this equation to estimate $\mathrm{NO}_{\mathrm{X}}$ emissions per hour:

Lbs of $\mathrm{NO}_{\mathrm{X}}$ emissions avoided per hour $=$ Power(w)*1 MWH/1000000 WH*6lbs/MWH

- 212 hectares of Trees absorb $9 \mathrm{lbs}$ of $\mathrm{NO}_{\mathrm{X}}$ per day or $0.375 \mathrm{lbs}$ per hour

- 1 acre of trees absorb $0.0172 \mathrm{lbs}$ of NOx per day or $0.0000328 \mathrm{lbs}$ per hour

Therefore, acres of trees needed $=\left(\mathrm{lbs}\right.$ of $\mathrm{SO}_{2}$ avoided per hour $) / 0.0000220 \mathrm{lbs}$ per hour

\begin{tabular}{|l|c|c|c|}
\hline \multicolumn{1}{|c|}{ Time of day } & $\begin{array}{c}\text { Power Output } \\
\text { (Watts) }\end{array}$ & $\begin{array}{c}\text { Lbs. } \mathrm{NO}_{\mathrm{X}} \text { emissions } \\
\text { avoided per hour }\end{array}$ & $\begin{array}{c}\text { Acres of Trees Required to } \\
\text { offset } \mathrm{NO}_{\mathrm{X}} \text { emissions }\end{array}$ \\
\hline $8 \mathrm{am}$ & & & \\
\hline Solar Noon & & & \\
\hline $4 \mathrm{pm}$ & & & \\
\hline
\end{tabular}

Conclusion Questions:

1) How do you feel solar power compares to reforestation or urban forests in terms of number of trees?

2) How many trees would it take to offset all United States carbon dioxide emissions (6 Billion tons/year)?

3) How many acres of trees would it take to offset all U.S. sulfur dioxide emissions (13 Million tons/year)?

Table 4- Renewable Energy to Reduce Pollution 


\section{Instrumentation:}

Similarly, students are introduced to instrumentation through the Strain Gage and Wheatstone bridge experiment as described below in Table 5.

\section{Laboratory 14. Strain Gage and Wheatstone Bridge}

In the Strain Gage and Wheatstone bridge experiment, students build and characterize a displacement measurement system. The measurement system consists of a cantilever beam with a strain gage mounted near its base, a Wheatstone bridge, and a digital voltmeter, as shown in figures 14.1 and 14.2. As a pre-lab assignment, students are asked to determine the expression for the output voltage in a quarter-bridge circuit (single-element varying). During the experiment, students are asked to measure the gage nominal resistance and select three identical resistors with this nominal value (as identical as possible) and build the quarter-bridge circuit. Then, students are instructed to follow the procedure described in Table 14.1 and create an Excel spreadsheet to record the acquired data. A typical plot of results is shown in figure 14.3.

\section{Lab 14. Strain Gage and Wheatstone Bridge Procedure}

Note: do not power up the system yet.

1. Adjust the beam system to be horizontal. The beam is horizontal when the gage resistance has its nominal value.

2. Displace the beam one millimeter at a time (down first), measuring the gage resistance until you reach $20 \mathrm{~mm}$. Take 3 cycles of up and down data. Compute the average of the three cycles.

3. Calculate the $\Delta \mathrm{R}$ value of the average measurement.

4. Plot a graph of resistance vs. displacement and calculate the sensitivity (in $\Omega / \mathrm{mm}$ )

5. Calculate the expected output voltage using the equation obtained in the prelab assignment.

6. Power up the system with $\mathrm{E}=5$ VDC. Displace the beam one millimeter at a time (down first), measuring the output voltage. Take 3 cycles of up and down data. Compute the average of the three cycles.

7. Note: you can remove the zero offset value.

8. Plot the data, output voltage vs. displacement and fit a straight line through them. Calculate the sensitivity of the measurement system (in $\mathrm{mV} / \mathrm{mm}$ ).

\section{Table 14.1. Procedure for Experiment 14.}

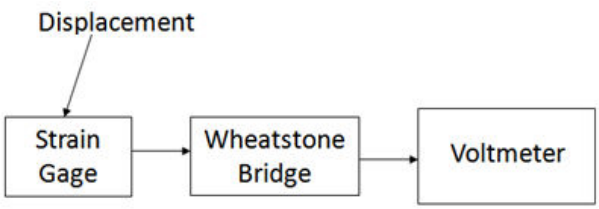

a) Block diagram: Displacement Measuring System

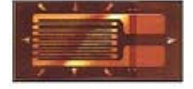

b) Metalic Strain Gage

Figure 14.1 Block diagram: Displacement Measuring System

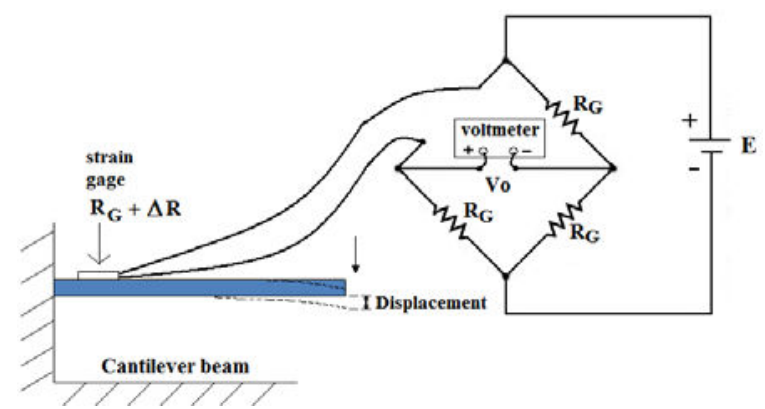

Figure 14.2. Quarter-Bridge Displacement Measuring System Set Up

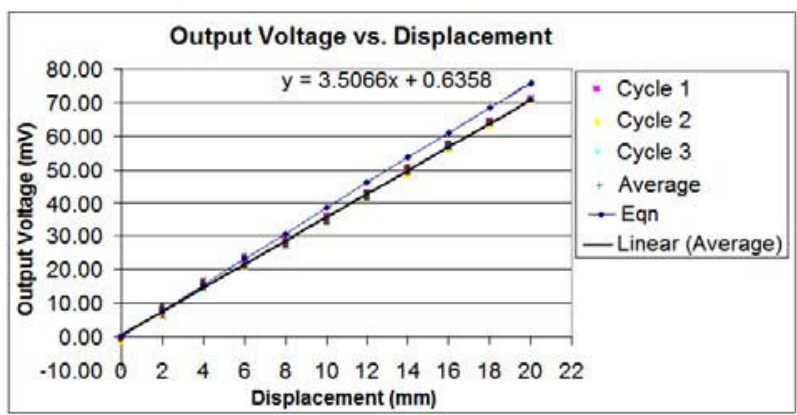

Figure 14.3. Typical results of the displacement measurement system

Table 5- Strain Gage and Wheatstone Bridge 


\section{Course Assessment}

For our course assessment and evaluation, the three assessment tools ${ }^{4}$ are used- course-level outcomes (CLO), continuous improvement efforts (CIE), and student course outcomes (SCO). These assessment tools have been developed by ET faculty and used extensively in the continuous improvement process and for ABET accreditation. As discussed, CLO form is completed by the instructor and states each course outcome relative to the program outcomes; identifies the assessment tools used to measure the student performance, and the corresponding rubric analysis result for each assessment. The instructor completes and submits CIE report which documents a strategy for instructional improvement for the next course offering. SCO evaluations form is an indirect measure used to collect feedback from students based on their perception of achieving the defined course outcomes.

To measure educational effectiveness, two assessment tools were used- Direct measures that correlate to student performance such as grades on a final exam - and indirect measures that provide feedback information such those obtained from a student survey. Figure 1 illustrates the entire course-level continuous improvement process which uses information collected from the three assessment tools (CLO, CIE, and SCO).

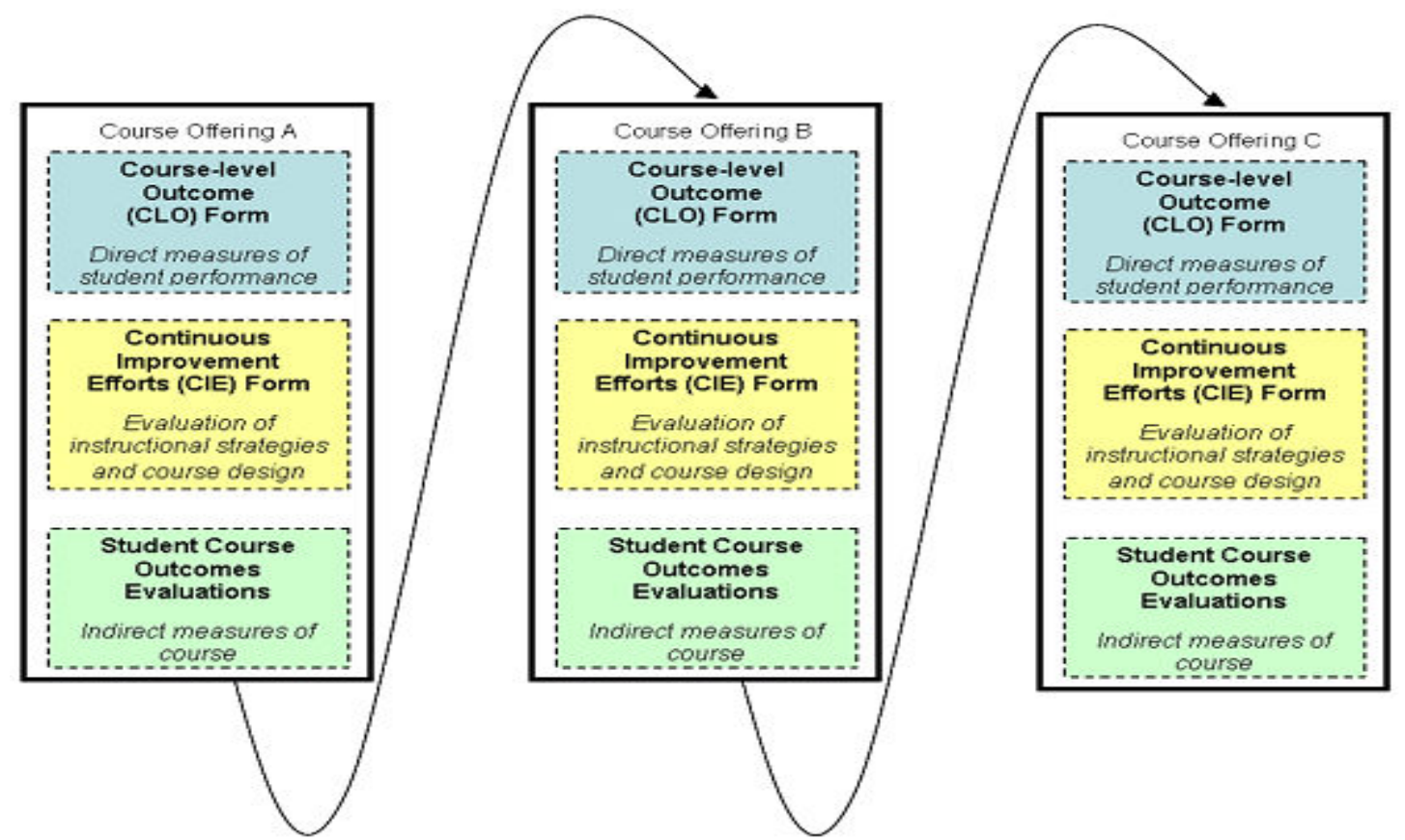

Figure 1 -Course-level Assessment \& Evaluation Process

As depicted in Table 6, the indirect and direct assessment results for fall 2008 (before the changes) and the Fall 2009 (after the changes). The columns labeled Student Course Outcome (SCO) are results from student surveys that are administered at the end of the semester. The columns labeled Course Level Outcomes (CLO) are the direct measure of the course outcomes prepared by the instructor based on student assignments, lab reports, quizzes, and exams. 


\begin{tabular}{|c|c|c|c|c|}
\hline \multirow[b]{2}{*}{ Course Learning Objectives } & \multicolumn{2}{|c|}{$\begin{array}{c}\text { Student Course Outcome } \\
\text { (SOC) }\end{array}$} & \multicolumn{2}{|c|}{$\begin{array}{l}\text { Course Level Outcome } \\
\text { (CLO) }\end{array}$} \\
\hline & $\begin{array}{l}\text { Composite } \\
\text { Average } \\
\text { (Fall 08) }\end{array}$ & $\begin{array}{l}\text { Composite } \\
\text { Average } \\
\text { (Fall 09) }\end{array}$ & $\begin{array}{l}\text { Composite } \\
\text { Average } \\
\text { (Fall 08) }\end{array}$ & $\begin{array}{l}\text { Composite } \\
\text { Average } \\
\text { (Fall 09) }\end{array}$ \\
\hline 1. Use ohm's law to solve and analyze electric circuits & 3.44 & 3.80 & 2.28 & 3.40 \\
\hline $\begin{array}{l}\text { 2. Determine resistance, voltage, and current in series, } \\
\text { parallel, and combinational circuits }\end{array}$ & 3.44 & 3.74 & 2.47 & 2.54 \\
\hline $\begin{array}{l}\text { 3. State the basic concepts and operation of DC and AC } \\
\text { machines }\end{array}$ & 2.88 & 3.54 & 2.91 & 3.18 \\
\hline $\begin{array}{l}\text { 4. Determine impedance, power factor, apparent, real, and } \\
\text { reactive powers in AC circuits }\end{array}$ & 3.16 & 3.16 & 2.31 & 3.00 \\
\hline $\begin{array}{l}\text { 5. Determine time constants and analyze transient response } \\
\text { of RL and RC circuits. }\end{array}$ & 2.88 & 3.51 & 2.34 & 3.32 \\
\hline $\begin{array}{l}\text { 6. State the resonance conditions of an RLC circuit and } \\
\text { calculate resonant frequency }\end{array}$ & 2.64 & 2.80 & 2.63 & 2.80 \\
\hline $\begin{array}{l}\text { 7. State the basic operation of diodes, transistors, power } \\
\text { supplies, and amplifiers }\end{array}$ & 2.08 & 2.00 & 3.19 & 2.96 \\
\hline 8. Apply the concepts of Wheatstone bridge and transducers & NA & 3.15 & NA & 2.75 \\
\hline 9. Learn to function effectively in laboratory groups & 3.24 & 3.00 & 2.5 & 3.20 \\
\hline $\begin{array}{l}\text { 10. Plan and conduct experiments in a disciplinary manner, } \\
\text { use standard laboratory instruments. Analyze, interpret, } \\
\text { troubleshoot and apply experimental results. }\end{array}$ & 3.56 & 3.23 & 3.17 & 3.70 \\
\hline $\begin{array}{l}\text { 11. Communicate effectively through the submission of } \\
\text { professional technical reports }\end{array}$ & 3.36 & 3.34 & 3.00 & 3.10 \\
\hline $\begin{array}{l}\text { 12. Investigate a given topic in technology and discuss } \\
\text { societal and ethical considerations }\end{array}$ & 3.20 & 3.37 & 3.38 & 3.39 \\
\hline $\begin{array}{l}\text { 13. Understand and have a commitment to quality, timeless, } \\
\text { and continuous improvement }\end{array}$ & NA & 3.40 & NA & 3.12 \\
\hline $\begin{array}{l}\text { 14. Draft and simulate the operation of electric circuits using } \\
\text { MultiSim }\end{array}$ & NA & 2.89 & NA & 3.2 \\
\hline $\begin{array}{l}\text { 15. Present a technology topic effectively in front of an } \\
\text { audience }\end{array}$ & NA & 3.65 & NA & 3.26 \\
\hline
\end{tabular}

\section{Table 6- Indirect and Direct Assessment Results}

The chart in Figure 2 presents data about the assessment results for 2008 and 2009 combined. As shown, most outcomes have positive incremental changes which are a good indication of improvement progress. On the other hand, the average of objective 5 dealing with the transient responses of RL and RC circuits fell below the 2.5 benchmark in fall 2008. Consequently, the course instructor completed a CIE report which documented a strategy for instructional improvement which resulted in better performance on that outcome in fall 2009. Furthermore objectives $8,13,14$, and 15 introduced as a result of the new course revision were all shown to be strongly satisfied in fall 2009. 


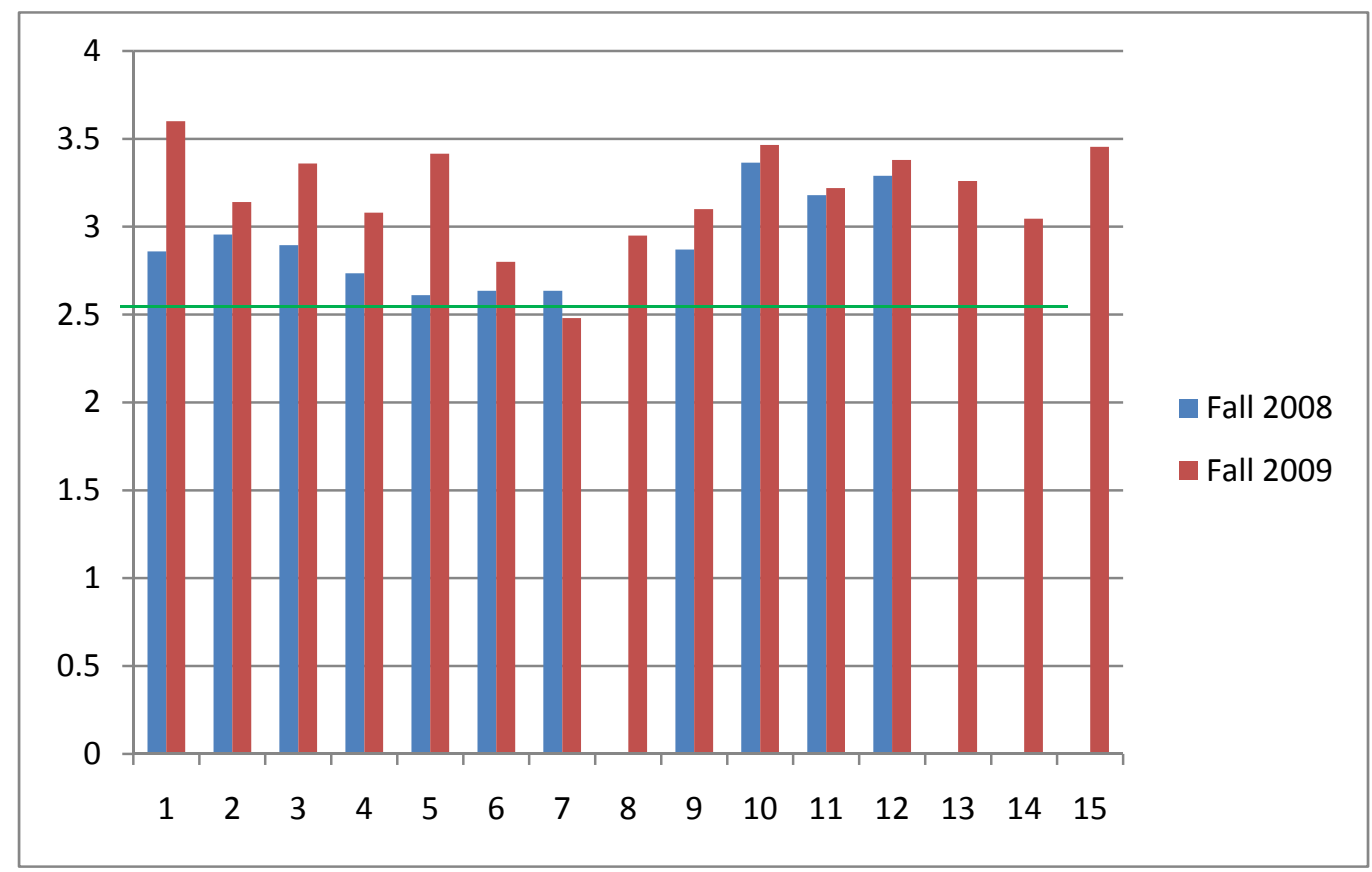

Figure 2- Summary of the Assessment Results

Additionally, the results of a student lab survey conducted at the end of fall 2009 showed overall satisfaction with the revised lab experimentations. Student responses to the quality of the lab manual, MutlSim simulation, pre-lab assignments, and suggestions for improvement are all included in the Appendix. However, there was some distinction in the responses between MET and EET students. For instance, most EET students reported no problem when asked about experiments involving the use of the oscilloscope and measuring equipment while MET students found experiments 14 and 15 the most interesting. It should be noted that the renewable energy experiment was not part in this survey since it was decided to start the next time the course is offered.

\begin{tabular}{|c|c|c|c|c|c|}
\hline Lab Experiments & $\begin{array}{l}\text { This experiment } \\
\text { was very } \\
\text { interesting. It } \\
\text { helped me learn } \\
\text { lot about the } \\
\text { concepts being } \\
\text { taught. }\end{array}$ & $\begin{array}{l}\text { This } \\
\text { experiment was } \\
\text { interesting. It } \\
\text { helped me } \\
\text { learn about } \\
\text { concepts being } \\
\text { taught. }\end{array}$ & $\begin{array}{l}\text { This experiment } \\
\text { was somewhat } \\
\text { interesting. It } \\
\text { helped me learn a } \\
\text { little about } \\
\text { concepts being } \\
\text { taught. }\end{array}$ & $\begin{array}{l}\text { This experiment } \\
\text { was not useful. It } \\
\text { did not help me } \\
\text { learn about the } \\
\text { concepts being } \\
\text { taught. }\end{array}$ & Average \\
\hline & Excellent-4 & Good-3 & Average-2 & Poor-1 & Scale of 4 \\
\hline $\begin{array}{l}\text { Lab 0- Safety in the } \\
\text { Electric Circuit Lab }\end{array}$ & 5 & 9 & 2 & & 3.19 \\
\hline $\begin{array}{l}\text { Lab 1-Safety, Equipment, } \\
\text { and Materials }\end{array}$ & 6 & 9 & 1 & & 3.31 \\
\hline $\begin{array}{l}\text { Lab 2- Open and Closed } \\
\text { Circuits }\end{array}$ & 12 & 2 & 2 & & 3.63 \\
\hline $\begin{array}{l}\text { Lab 3- Current and } \\
\text { Voltage }\end{array}$ & 13 & 3 & & & 3.81 \\
\hline Lab 4- DC Series Circuits & 11 & 5 & & & 3.69 \\
\hline
\end{tabular}




\begin{tabular}{|c|c|c|c|c|c|}
\hline $\begin{array}{l}\text { Lab 5- DC Parallel } \\
\text { Circuits }\end{array}$ & 10 & 6 & & & 3.69 \\
\hline Lab 6- The Oscilloscope & 3 & 4 & 6 & 3 & 2.44 \\
\hline $\begin{array}{l}\text { Lab 7- Capacitors in DC \& } \\
\text { AC Circuits }\end{array}$ & 7 & 8 & 1 & & 3.37 \\
\hline $\begin{array}{l}\text { Lab 8- Inductors in DC \& } \\
\text { AC Circuits }\end{array}$ & 7 & 9 & & & 3.44 \\
\hline $\begin{array}{l}\text { Lab 9- RLC Circuits and } \\
\text { Resonance }\end{array}$ & 7 & 7 & 1 & 1 & 3.25 \\
\hline Lab 10- The Transformer & 8 & 6 & 1 & 1 & 3.31 \\
\hline $\begin{array}{l}\text { Lab 14- Strain Gage and } \\
\text { Wheatstone Bridge }\end{array}$ & 6 & 7 & 3 & & 3.19 \\
\hline $\begin{array}{l}\text { Lab 15- Relays, Switches, } \\
\text { and DC Motor Reversing }\end{array}$ & 10 & 4 & 2 & & 3.5 \\
\hline
\end{tabular}

Table 7- Summary of the Student Lab Survey

\section{Conclusions}

In this paper, we described our experience teaching a multidisciplinary course in an Engineering Technology program. We described how the redesign of the laboratory component has greatly enhanced the student learning experience independently of their majors of studies. It was observed that activities relating concepts to real world applications were most appealing. For instance, students enjoyed performing experiments involving the use of transducers. Assessments results including direct and indirect measurements to meet certain accreditation criteria were also discussed in this paper. Several lessons learned from this course revision process for in future improvement. Although simple analysis was used in this study, one may easily deduce that most students are appreciative of the lab revision and wanted the simulation assignments to continue. Furthermore, educators should always strive to keep students engaged by employing a variety of teaching techniques that satisfy different learning styles. Finally, The best lessons are derived from student feedback which may seem conflicting at first but can otherwise provide valuable insight.

\section{Bibliography}

1. L. Feisel and A. Rosa, "The Role of the Laboratory in Undergraduate Engineering Education", Journal of Engineering Education, January 2005, pp. 121-130.

2. C. Pomales-Garcia, Y. Liu, "Excellence in Engineering Education: Views of Undergraduate Engineering Students", Journal of Engineering Education, July 2007, pp. 253-262.

3. Framk Splitt, "The Challenge to Change: On Realizing the New Paradigm for Engineering Education", Journal of Engineering Education, April 2003, pp. 181-187.

4. Youakim Al Kalaani, "Effective Approach to Assess Teaching Industrial Electronics", Proceedings of the 2008 ASEE Annual Conference, Austin, TX, June 14-17, 2009 


\section{Appendix}

\section{Brief description of the lab experiments}

Laboratory 1. Safety, Equipment, and Materials. This experiment introduces students to safety issues in the laboratory, the basic material and equipment, and breadboards and multimeters. Laboratory 2. Open and Closed Circuits. In this experiment students learn about open and closed circuits, calculation of power, and how to use Ohm's law. Verification of experimental results using MultiSim.

Laboratory 3. Current and Voltage. This experiment introduces students to the measurement of voltage $\mathrm{s}$ and currents in DC circuits. Also introduces the LED device. Verification of experimental results using MultiSim.

Laboratory 4. Series Circuits. In this experiment students measure voltages and currents in Series Circuits. Students also calculate power. Verification of experimental results using MultiSim.

Laboratory 5. Parallel Circuits. This experiment reinforces student's skills in measuring voltages and currents in DC circuits. Calculation of power is also performed. Verification of experimental results using MultiSim.

Laboratory 6. The oscilloscope. In this experiment students are introduced to AC signals and how to use the oscilloscope. Students perform voltage and frequency measurements using the oscilloscope.

Laboratory 7. Capacitors in DC and AC circuits. In this experiment students learn how capacitors perform in DC circuits and how they perform in AC circuits. Verification of experimental results using MultiSim.

Laboratory 8. Inductors in DC and $\mathrm{AC}$ circuits. In this experiment students learn how inductors perform in DC circuits and how they perform in AC circuits. Verification of experimental results using MultiSim.

Laboratory 9. RLC Circuits and Resonance. In this experiment students determine the voltages and currents in series and parallel RLC circuits. Students learn the characteristics of RLC circuits under resonance conditions. Verification of experimental results using MultiSim.

Laboratory 10. The Transformer. In this experiment students learn to determine the turn ratio of a transformer. Students also measure currents and voltages across a transformer.

Laboratory 11. Renewable Energy to Reduce Pollution. In this experiment students learn to determine the amount of pollution produced to generate electric power. Students also determine the number of trees needed to offset pollution. Students determine the power generated by a solar photovoltaic system.

Laboratory 12. Solar Power Efficiency. In this experiment students collect data about solar irradiation, temperature and wind speed. Students calculate efficiency if current solar system depending on weather conditions.

Laboratory 13. Angular Position Measuring System. In this experiment students learn about the stages of a generalized measuring system. Students use voltage divider circuit to convert changes in resistance into voltages.

Laboratory 14. Strain Gage and Wheatstone Bridge. In this experiment students get familiar with strain gages and their characteristics. Students use a Wheatstone bridge to convert changes in resistance to changes in voltage. 
Laboratory 15. Relays, switches and DC Motor Reversing. In this experiment students get familiar with terminology for switches and relays. Students use switches and relays to perform motor reversing in DC motors.

\section{Student responses to Lab Survey Questionnaires:}

A) The Lab Manual was: Organized and Clear: 16 Poor and Confusing: 0

- It was very easy to find the experiments.

- Easy to read and do.

- All the labs were very well put together and were very to the point.

- It was confusing at times but mostly straightforward.

- Most of the labs were easy to understand put some were difficult to set up.

- It had great organization that allowed the lab to run smoothly.

- Everything was clear and the procedure was explained well.

- They were all straight forward and easy to understand.

- Could use some work to correct Grammar.

- It was pretty easy to follow step by step.

- Everything was clear and straight forward.

- All necessary info provided with clear directions.

- For the most part I understood what was being done.

B) How did you find the Pre-lab assignments? Useful: 13 Not Useful: 3

- It helped me to understand the lab better.

- Helped to set me ready for lab.

- Some of them were a little confusing but they all helped prepare for the lab.

- They helped to understand the general idea of what the lab was about.

- They prepared me for the labs.

- Useful, it allowed you to get an insight on the actual project.

- Gave you a good understanding of the experiment.

- They were basically sample calculations and made sure we know what we were doing.

- Sample calculations helped ensure the lab went smoothly.

- Just simple calculations.

- The pre-lab showed what to expect from the lab that week.

- Seemed like busy work.

- Referring on calculations and provided info for lab.

C) The MultiSim simulation helped me understand the lab better Yes: 6 No: 10

- It was not helpful.

- We knew what was supposed to learn.

- The labs we used MultiSim on helped but we did not use enough.

- It helped to create circuits through trial and error without breaking anything.

- Somewhat difficult to relay the simulation to the actual lab. 
- It really did not do anything more than the lab itself.

- Explained how the actual circuit was supposed to work.

- Did never understand it.

- Not very available.

- The MultiSim showed how the circuit should work.

- It is easier to see the real experiment.

- Nothing but redrawing the circuits was no help at all.

D) What recommendations for improvements do you have?

- None. The lab experience was great overall.

- Please have more fuses in the lab.

- Have more fuses and explain how to read meters at beginning of course.

- None. Great as it is.

- Newer equipment.

- Clearer instructions on some of the labs. Better simulator. 